\title{
8. DESIGN IMPROVEMENTS TO THE DCS CORE BARREL AND SAMPLING SYSTEMS ${ }^{1}$
}

\author{
G.L. Holloway ${ }^{2}$
}

\section{EXECUTIVE SUMMARY}

The core barrel developed for use with the diamond coring system (DCS) was enhanced with several new components, along with three types of sediment sampling systems. A complete suite of fishing tools for recovery of both the inner barrel assemblies and outer core barrel was developed to complement the coring hardware. Primary hardware changes to the core barrel amounted to introducing a float valve into the outer core barrel and adding a basket-style core catcher to be run in tandem with the conventional collet-style catcher on the inner barrels. Extended crown bits were specifically designed for fractured and abrasive basalts expected at the East Pacific Rise (EPR) site for Ocean Drilling Program (ODP) Leg 142. In addition to the coring hardware, a DCS hydraulic piston sampler was designed for use with the existing DCS core barrel.

Problems experienced with the secondary heave compensator on the DCS platform presented considerable difficulty in attempting to maintain constant weight on bit. While coring, the diamond bits were repeatedly impacted on the bottom of the borehole, causing catastrophic bit failure. In the course of attempting to correct the secondary heave compensator problems, some material was recovered that had been jammed into the inner barrel. No cores were actually cut with the DCS during Leg 142. This chapter describes the hardware additions to the DCS coring system and the deployment sequence necessary for operation of the hydraulic piston sampler. Discussion of the diamond bits that were run and suggestions for improvements to the system are also presented.

\section{INTRODUCTION}

A modified diamond core barrel was designed for use in conjunction with the DCS drilling equipment. This core barrel was first introduced on ODP Leg 132, when both mining and oil-field technology were integrated to produce a stronger, more robust core barrel. A detailed system description of the modified HQ-3 core barrel is presented in the Leg 132 Initial Reports volume (Storms, Natland, et al., 1991). The mechanical design of the core barrel and support hardware performed almost flawlessly throughout Leg 132 despite coring only $259 \mathrm{ft}(79 \mathrm{~m})$. The $259 \mathrm{ft}(79 \mathrm{~m})$ encompassed 42 core runs and almost 20 hours of continuous rotation on the bottom of the hole. Some shortcomings with the system were found primarily in the area of core retention and sampling of softer and/or granular-type material.

Several small modifications were made to the core barrel to correct these retention deficiencies. These changes were the addition of a basket-style core catcher and a float-valve assembly, and the introduction of both shelby-tube and split-spoon-type samplers. The shelby-tube sampler could be deployed either as a standard push sampler or as a hydraulic piston sampler. Bit design was another area in which a considerable amount of emphasis was placed on improving the performance and prolonging the life of the core bit. Changing a

\footnotetext{
${ }^{1}$ Storms, M.A., Batiza, R., et al., 1993. Proc. ODP, Init. Repts., 142: College Station, TX (Ocean Drilling Program).

${ }^{2}$ Ocean Drilling Program, Texas A\&M University, College Station, TX 77845-9547, U.S.A.
}

core bit still requires approximately $24 \mathrm{hr}$ if the bit is ruined or worn out. This is an involved affair which requires several operations of pipe and tubing handling for proper space-out of the DCS platform. The time required to change out a bit is somewhat dependent on water depth; however, a major portion of the time is allotted to rigging up/down for running the tubing and the platform stripover/handling operations. A schematic of the DCS platform spaced out to the $45-\mathrm{ft}$ $(13.7 \mathrm{~m})$ elevation is presented in Figure 1.

This chapter addresses the new hardware developed for sampling the softer-type sediments, primarily cohesive and granular-type material. Included is a description of the new core bits developed and core retention devices designed to complement the existing hardware. Discussion of the fishing tools available for the DCS tubing and core barrels is also presented. Figure 2 presents a flow diagram of the different coring and sampling options available for the core barrel developed for the DCS.

\section{CORE-BARREL IMPROVEMENTS}

No significant changes were made to the core barrel (Fig. 3) initially developed for Leg 132. However, some additional hardware was added to enhance core recovery and prevent the DCS tubing from being swabbed during inner barrel retrieval. Probably the most notable hardware changes concerning the core barrel were the addition of some sampling hardware and core retention devices. The primary modifications to the barrel were:

1. the spindle-bearing housing was modified to encapsulate the bearing assembly,

2. the inner barrel stabilizer was modified to include a float valve (plastic or steel), and

3. a basket-style core catcher was added which could be run in tandem with the standard collet-type catcher on the inner barrel.

The modification to the spindle bearing consisted of lengthening the part so that the two bearing sets in the swivel assembly would be fully enclosed. This encapsulation prevents the roller bearings from lodging themselves around the inner barrel, in turn preventing the tubing from having to be pulled in the event of total bearing failure. The addition of the float valve was made for formations where softer sediments (clays and/or granular material) might be encountered. The float valve was specifically designed to prevent swabbing the borehole when used in conjunction with the push samplers or hydraulic piston sampler. It possibly could be used in the coring mode; however, the fingers of the float valve may interfere with the inner barrel's need to remain stationary during rotation until core begins entering the inner barrel. Further testing in this mode is required before we can ascertain if the float valve is appropriate for use in the coring modes. The float valve is basically an inverted basket-style core catcher. The fingers of the two prototypes developed were made from different materials. The first style used thin metal sheet cut into the appropriate size and shape for forming a full closure-type float valve. This metal sheet was then attached to a ring before being pressed into the modified lower stabilizer. The second type of float valve was machined from a harder type of plastic material. It was separate from the modified brass stabilizer ring which was placed directly behind it 


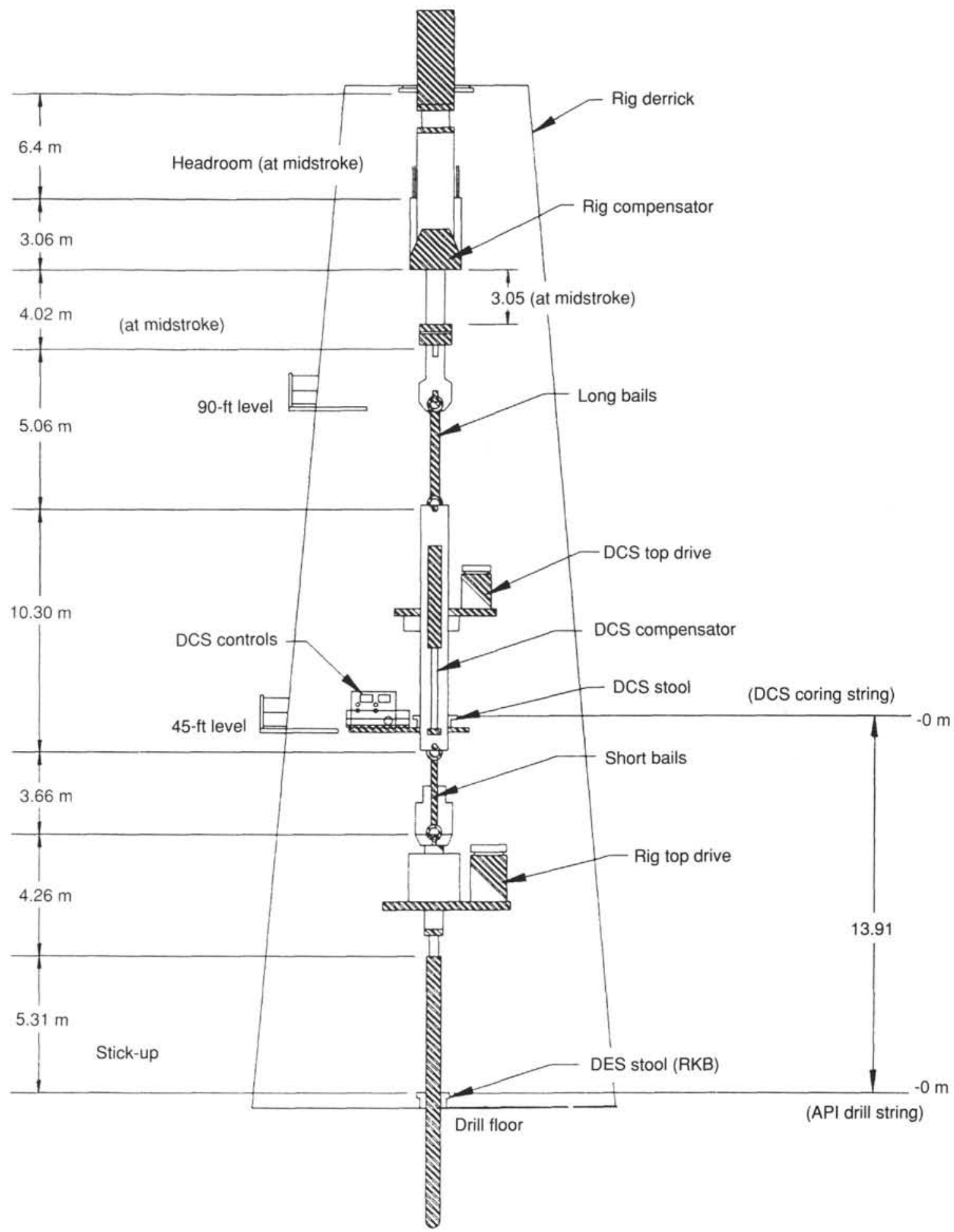

Figure 1. DCS derrick stack-up. (API = American Petroleum Institute; RKB = rotary kelly bushing.) Dimensions in inches unless otherwise noted.

inside the core bit. A general schematic of the float-valve assembly is illustrated in Figure 4.

Probably the most important modification to the core barrel was the addition of the basket style-core catcher. This core catcher could be run in tandem with the conventional collet-style catcher in formations where granular material or very fractured rock might be encoun- tered. The basket catcher was made from very thin sheet metal (0.06 in. [1.5 mm]) which was then brazed into the top of a slightly modified collet-catcher ring. The full-closure basket catcher was designed so that the butyrate liners could still be run inside the inner tubes. An inner barrel is illustrated both with and without the basketstyle core catcher in Figure 4. 


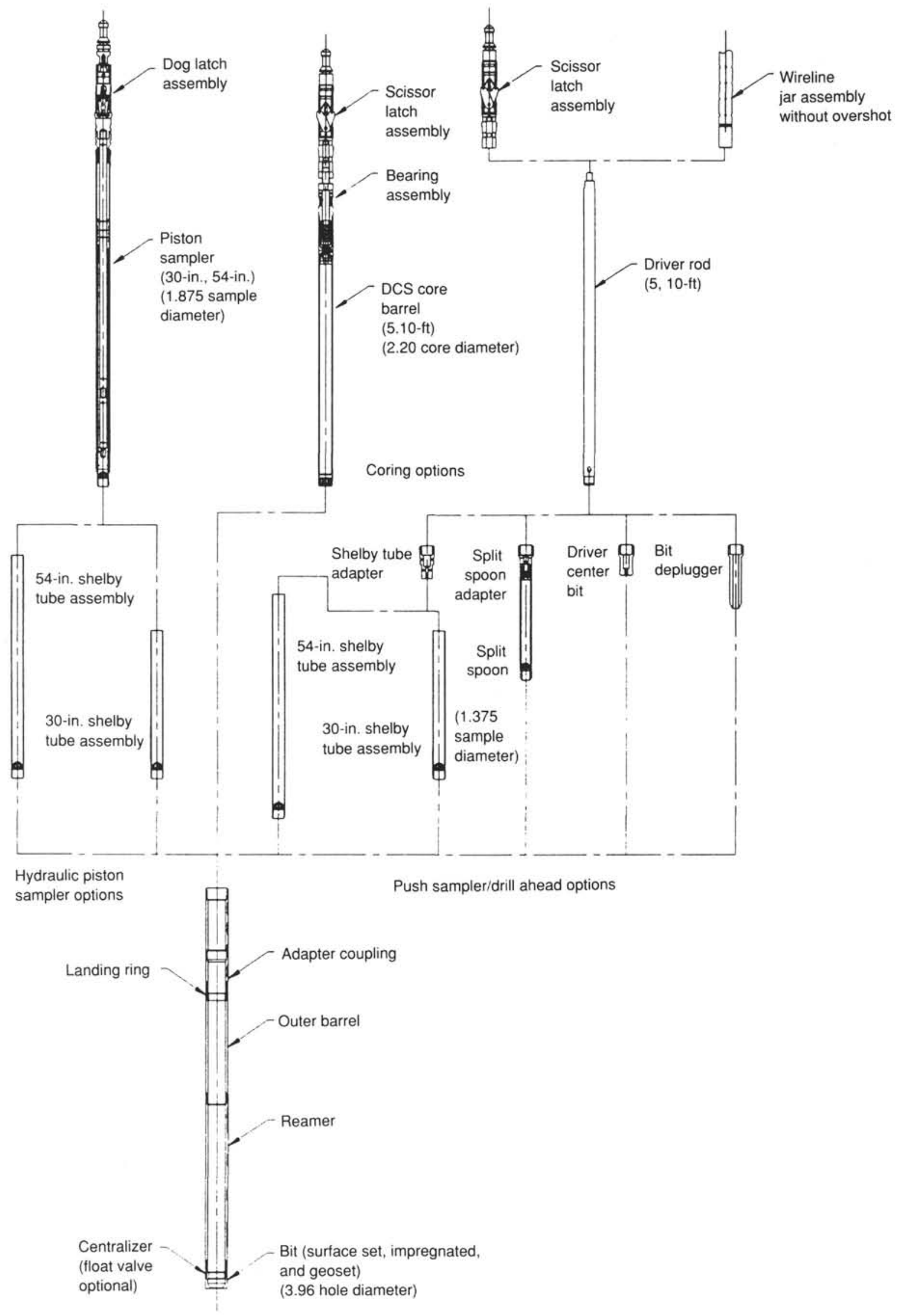

Figure 2. Core-barrel assembly options. 

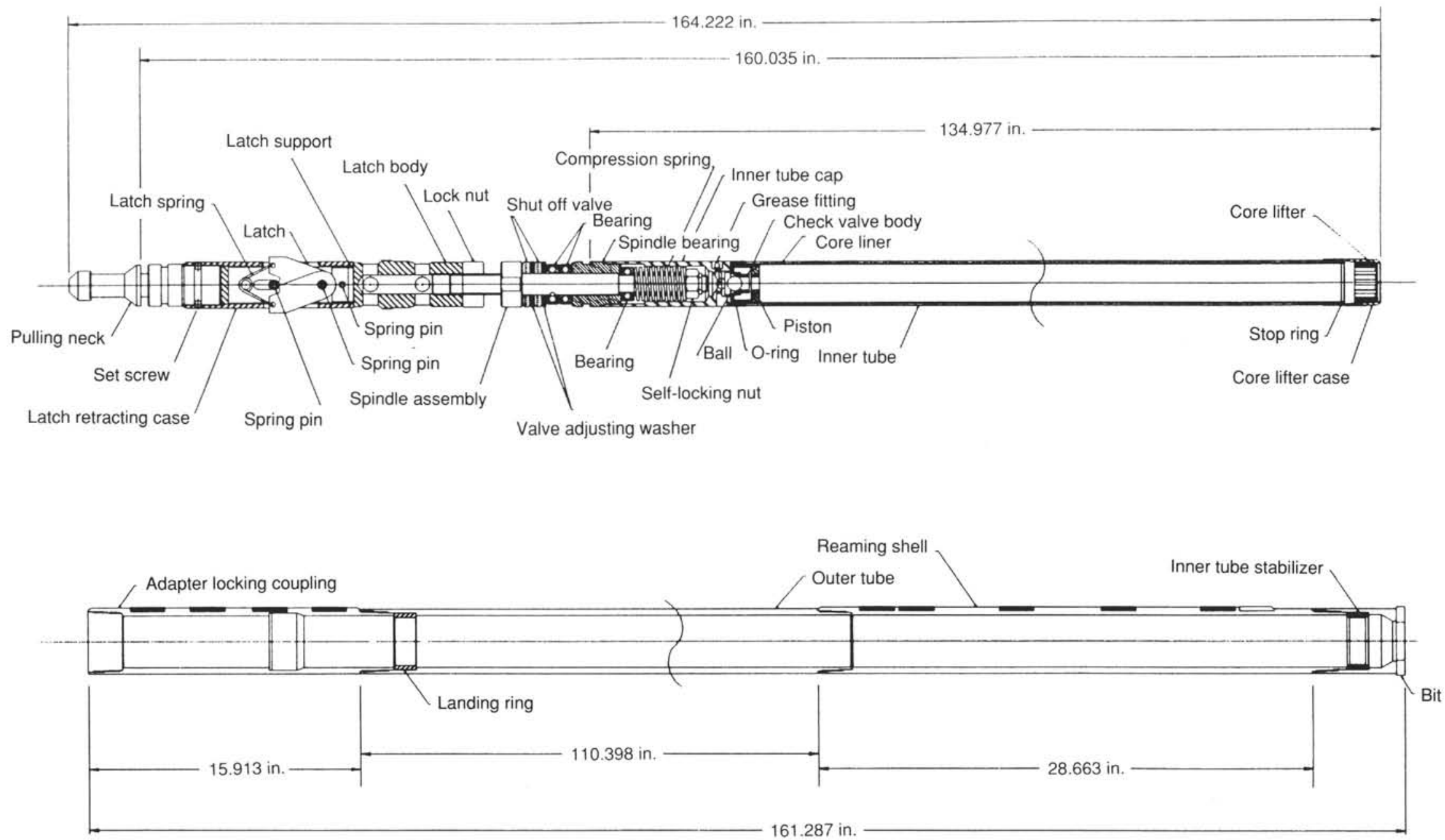

Figure 3. DCS core-barrel assembly (10 ft; 3.96-in. $\mathrm{OD} \times 2.2$-in. ID). 


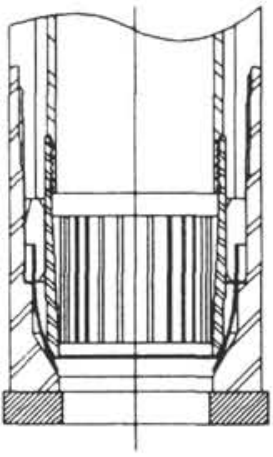

Core barrel collet-type catcher

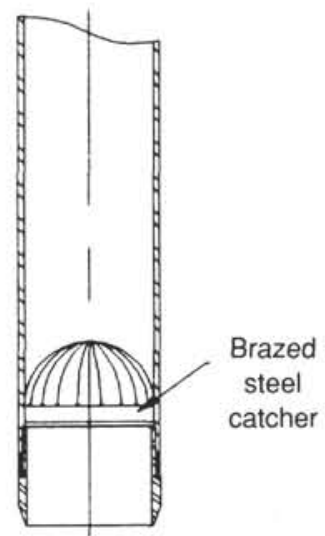

Shelby tube basket catcher

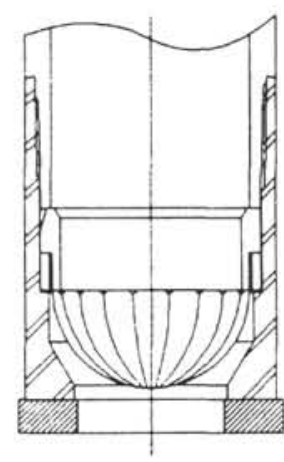

Core barrel float valve

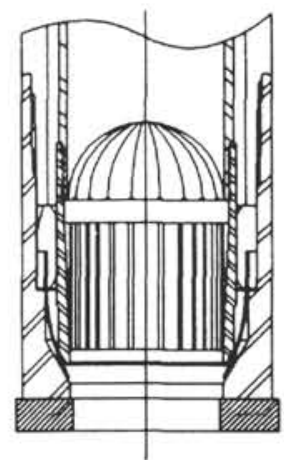

Core barrel collet-type with basket catcher

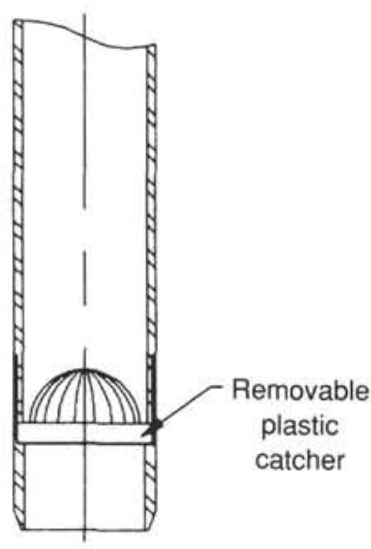

Split spoon basket catcher

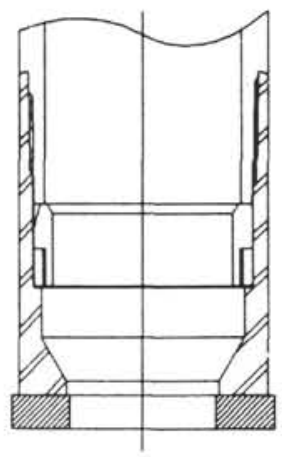

Core barrel without float valve
Figure 4. Core-catcher/float-valve assembly options.

\section{SEDIMENT SAMPLERS}

\section{Hydraulic Piston Sampler}

A hydraulic piston sampler was developed for the DCS to be used in certain situations in which sampling might be required as close to the seafloor as possible or where formations might include alternating layers of hard rock and soft sediments with depth. Locations such as the Shatsky Rise, where formations of interlayered chalk and cherts exist or where shallow layers of sediment might overlay indurated hard-rock formations are ideal locations for the hydraulic piston sampler. The mechanics of the hydraulic piston sampler are very similar to ODP's advanced piston corer (APC). It is fired into the formation by shearing one to three small pins by a build-up of drill-string mud pressure. The hydraulic piston sampler is illustrated in Figure 5.

Presently, two lengths of sample tubes are available for the piston sampler: a 30 -in. $(76.2 \mathrm{~cm})$ or 54 -in.-long $(137 \mathrm{~cm})$ piston barrel. The longer shelby tube is the sampler of choice, even though the 30 -in. $(76.2 \mathrm{~cm})$ shelby can be run. Sample diameter for the piston sample is $1.935 \mathrm{in}$. (49.1 mm). Due to limited height available with the DCS top drive, the piston sampler was designed to be broken down into two parts before being lowered down from the suspended platform. This was accomplished by having the piston rod made in two pieces so the upper rod section and latch assembly could be removed prior to handling the inner barrel and sample tube.

Two pistons are used in the hydraulic piston sampler. The upper piston, which is attached to the shelby tube, is the driver piston that pushes the sampler into the formation. The three shear pins used to regulate firing resistance reside in the upper portion of this piston. The lower stationary piston is principally used to keep the sediment that enters the tube from further disturbance. It is connected at the end of the piston rod. The shelby tube is connected to the upper piston with $3-1 / 4$-in. $(6.35 \mathrm{~mm}) 20 \mathrm{UNC}-2 \mathrm{~B}$ allen screws. A nose cone is attached to the lower end of the shelby tube with a basket catcher brazed into the inner diameter (ID). The nose cone is threaded onto the shelby tube in order for it to be removed before extruding the sample from the shelby tube. A schematic of the lower portion of the piston sampler is illustrated in Figure 6.

Because the sampler must be partially broken down before being lowered to the rig floor, a few extra steps are required in the disassembly procedure. These steps, along with whole deployment scenario, are outlined in the following list and graphically illustrated in Figure 7.

1. Raise the outer barrel off the bottom of the hole,

2. Lower piston sampler into outer barrel with wireline,

3. Pressurize line wiper, then activate piston sampler with mud pressure,

4. Lift outer barrel with top-drive feed cylinders approximately the same distance that sampler was deployed into the formation,

5. Retrieve piston sampler with overshot,

6. Raise piston-sampler latch assembly above tubing stick-up and place C-clamp onto lower body piston,

7. Remove overshot,

8. Attach lifting angle to pulling neck,

9. Unscrew upper latch body from lower latch body,

10. Raise upper latch body with piston rod until fully retracted,

11. Unscrew upper piston rod from lower piston rod,

12. Attach lifting angle around pulling neck sub, remove C-plate, and raise inner tube and shelby tube out of pipe,

13. Lower inner tube with shelby tube inside to rig floor,

14. Remove lifting sub and lower body assembly from inner tube,

15. Lift out shelby tube from inner tube,

16. Remove upper piston from shelby tube,

17. Remove lower piston and rod from shelby tube, and

18. Unscrew basket catcher and extrude sample tube.

\section{Push Samplers}

In addition to the hydraulic piston sampler, the two sizes of shelby tubes can also be used as conventional push samplers. These samplers are made up on the driver rod assembly and crossed over to the sample tubes with shelby-tube adapters. When deploying either sampler the bit must be off the bottom the distance the sample tube protrudes out 


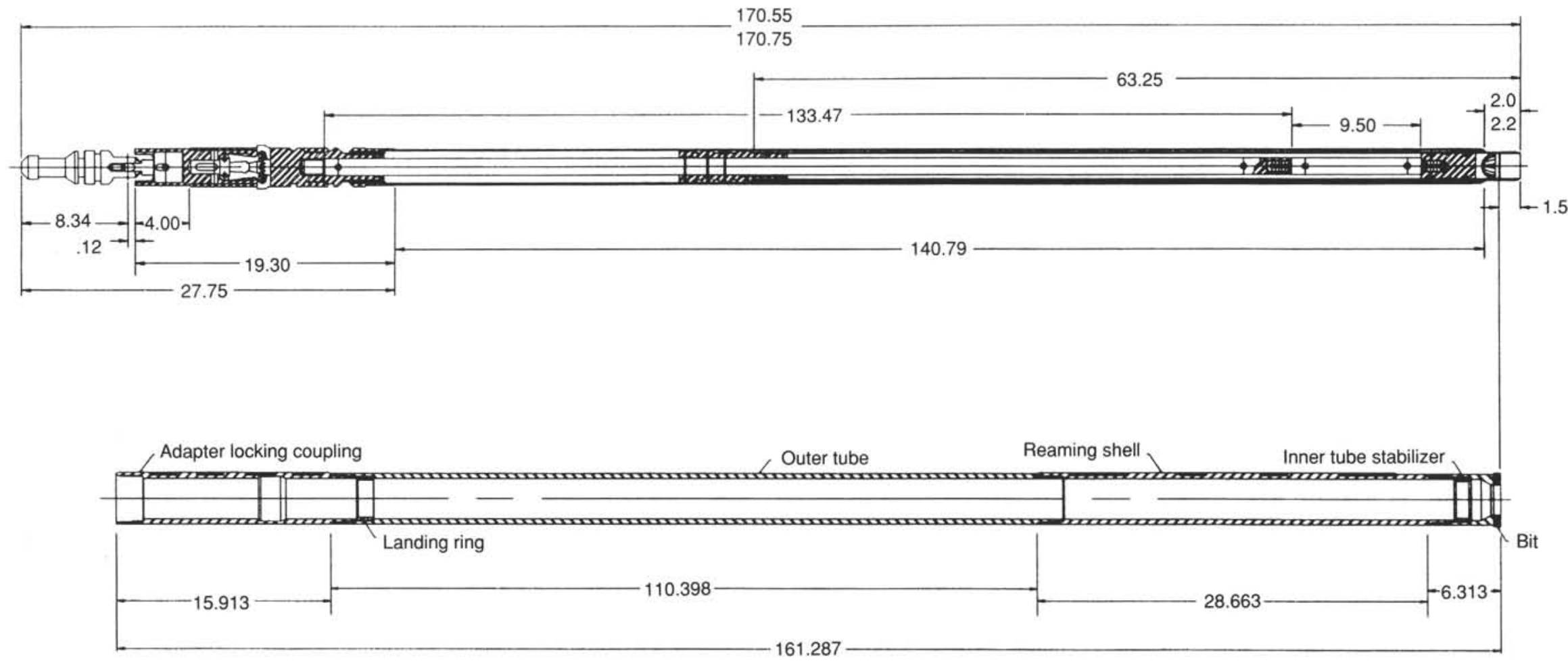

Figure 5. DCS piston-sampler assembly (10 ft; 3.96 -in. $\mathrm{OD} \times 1.935$-in. ID). Dimensions in inches. 


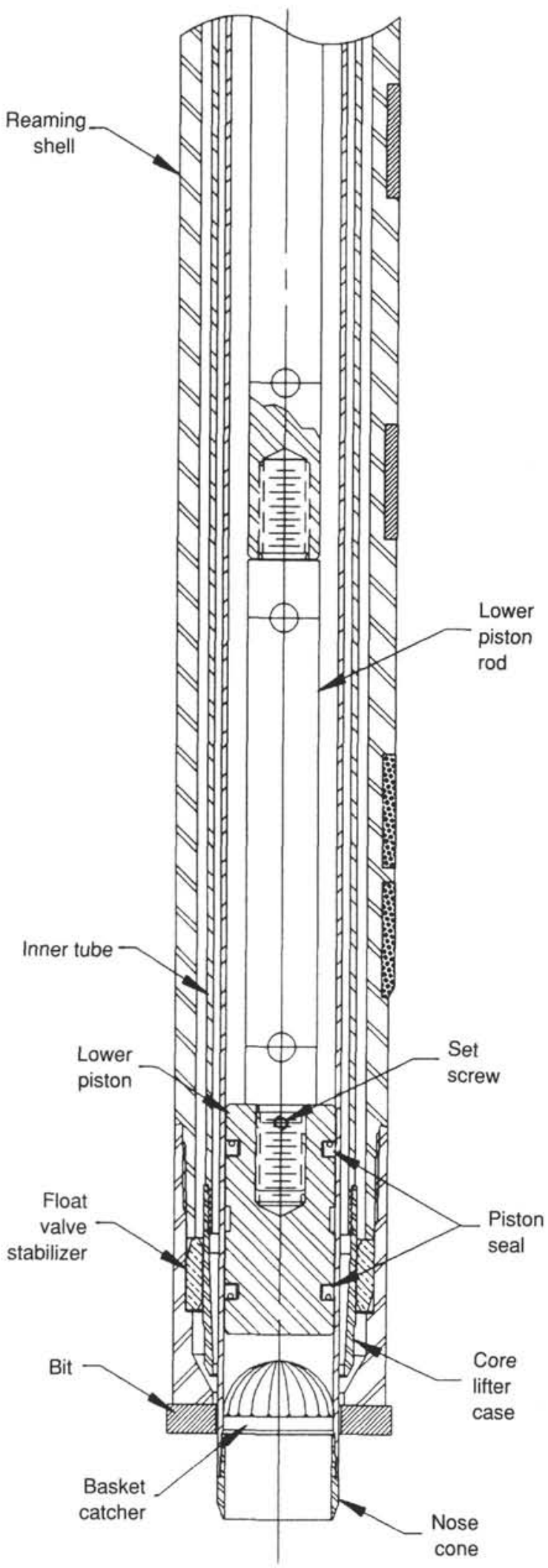

Figure 6. Piston-sampler detail. the end of the bit, with the driver rod assembly latched into the outer tube. The samplers can be lowered on the wireline or dropped and allowed to free fall. The shelby tube is then pushed into the formation by lowering the feed cylinders the length of the tube in a compensated mode. The feed cylinders must again be raised to free the sample tube before removing the sampler with the wireline overshot. The same basket-style catcher and nose-cone assembly outlined in the previous section is again used. The crossover adapter connecting the shelby tube to the driver rod has a ball-check valve inside to help prevent the sample from being lost. A schematic of the push sampler is provided in Figure 8.

\section{Percussion Samplers}

An alternate means of sampling can be performed with a splitspoon sampler. This sampler can be deployed by one of two means: the driver rod assembly can be used to push the split-spoon sampler into the formation or it can be driven into the formation with the wireline-operated mini-jar assembly. The split spoon sampler takes a 1.50 -in.-diameter $(38.1 \mathrm{~mm}) \times 18$-in.-long $(45.7 \mathrm{~cm})$ sample. The split design allows the barrel to be opened up similar to a clam shell in order to retrieve the sample in place of extruding it like the shelby tube. The robust design is ideal for denser materials such as coarsegrained sands. A plastic basket-style core catcher is included in the nose cone for core retention. The upper adapter has a ball-check valve to encourage a suction force in order to retain the sample. A schematic of the split-spoon adapter is illustrated in Figure 9.

\section{CORE BITS}

There were only six additional diamond core bits purchased for Leg 142 . All of the bits were slightly modified with extended crowns in an attempt to prolong the life of the bit. These bits were furnished by Longyear, Hobic, and Dimatec. All three of the manufacturers recommended impregnated design with diamond mesh sizes ranging between 20/25 to 25/35 for the Longyear and Hobic bits and 30/50 for the Dimatec impregnated bits. Longyear and Hobic both provided a Series 1 and 2 (hard formation), and the Dimatec bits fell more closely into the medium to medium-hard formation range. Water courses between the different manufactures ranged from 8 to 10 per bit with sizes typically around $1 / 8 \mathrm{in}$. wide $(3 \mathrm{~mm}) \times 7 / 16$ in. deep $(11 \mathrm{~mm})$. A complete listing of these bits, along with others available during Leg 142, is presented in Table 1.

\section{FISHING TOOLS \\ Outer Barrel Tools}

Since several new tools were added to the core-barrel inventory, the complexity of recovering an inner core barrel or other type of sampling tool lost downhole could no longer be addressed with a single piece of fishing hardware. In an attempt to limit the number of times that the DCS tubing string might be potentially pulled, a suite of fishing hardware was assembled. Fishing options for DCS tubing or outer core barrel which might be either dropped or twisted off could be recovered with one of the following types of tools:

\section{Itco-type Bowen releasing spear, \\ 2. taper tap, or \\ 3. hook spear.}

A schematic of these tool is provided in Figure 10. The Bowen releasing spear should probably be used first in most instances since it has fewer tendencies to further damage the connection being fished. This tool also has an optional nose nut covered with Kutrite which can be used for milling a tubular or box connection if it is partially damaged. 


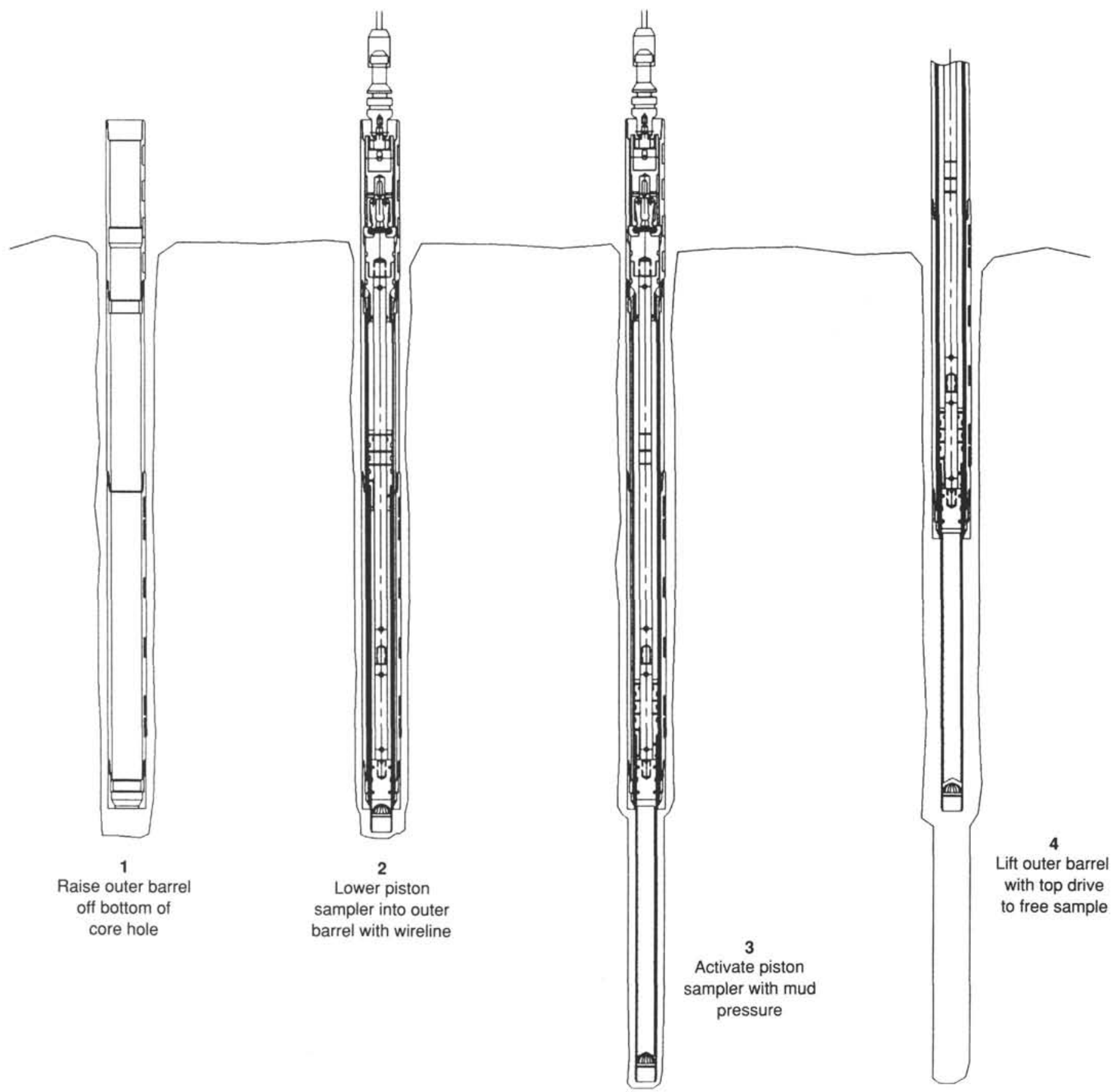

Figure 7. Piston-sampler deployment sequence.

\section{Inner Barrel Tools}

Four styles of inner barrel/piston-sampler fishing tools were developed to complement the outer barrel fishing tools:

1. inner barrel hook spear,

2. piston/inner barrel tube tap,

3. shelby tube tap, and

4. piston rod bell tap.

These tools can be run on the wireline jar or on a sinker-bar assembly. Traditionally, taps should be rotated for positive engagement. As a smaller string is not presently available, rotating the tap inside the DCS tubing is not possible. Therefore, the only method of latching onto the fish is to drive the tap onto/into the end looking up. As in the case of the hook spear designed for outer barrel/tubing recovery, the inner barrel hook spear should again be used as the last resort. It is a useful spear, but positive engagement will usually result in the recovered fish being totally destroyed. A schematic of the available fishing options for the inner barrel/piston sampler is presented in Figure 11.

\section{PERFORMANCE}

\section{Core Barrel}

The core barrel again operated trouble-free throughout the leg even though it saw limited use. Total rotational time during the leg 


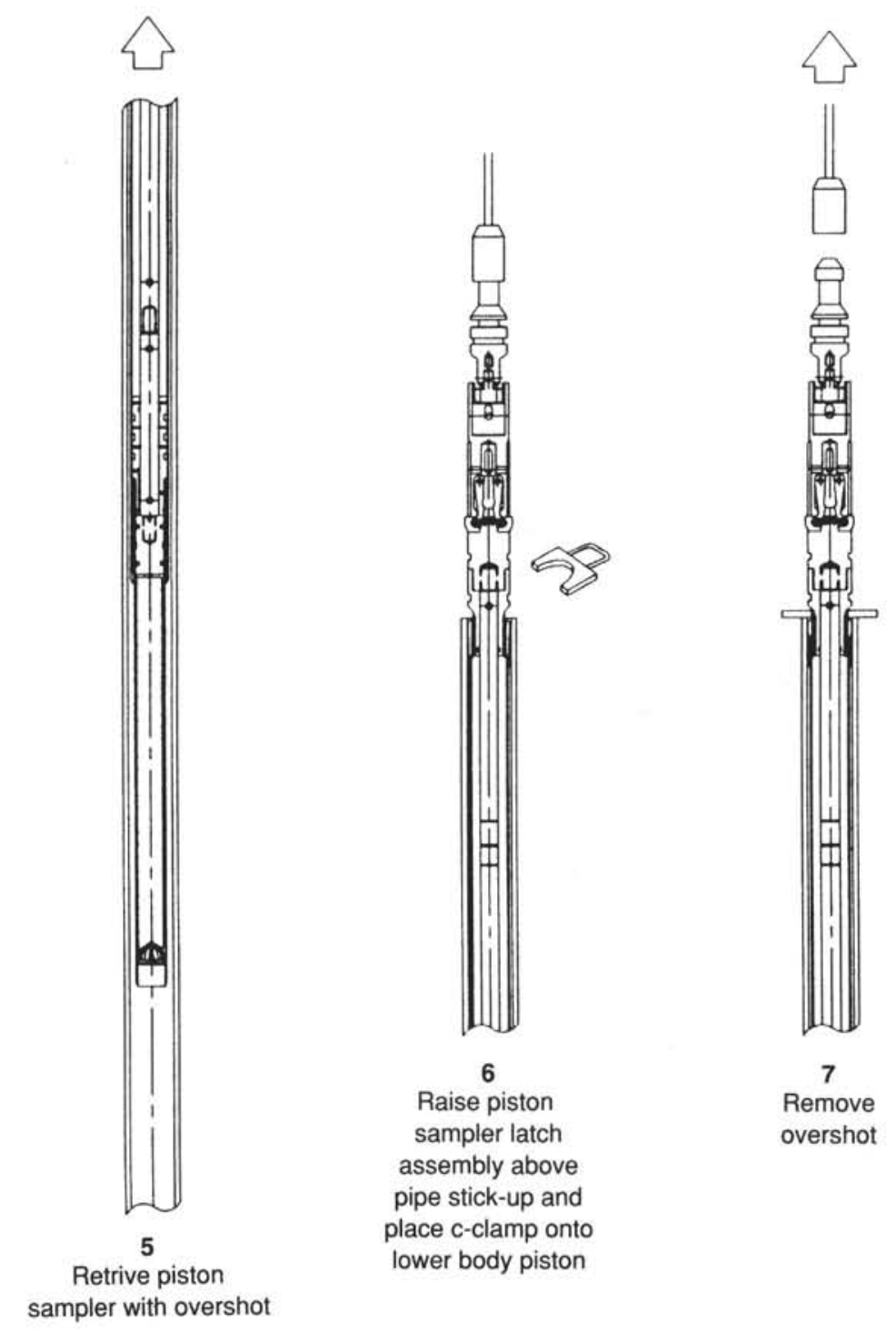

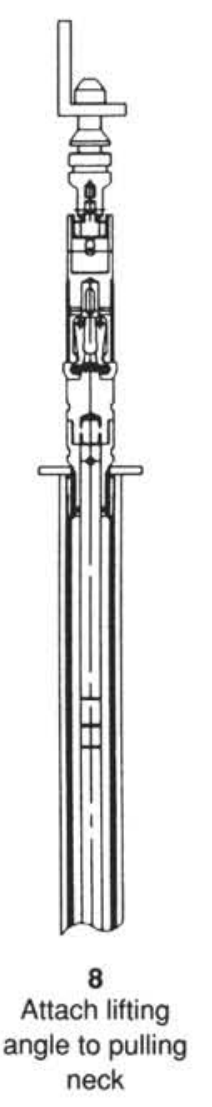

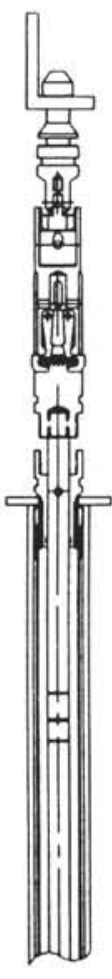

9

Unscrew upper

latch body from lower latch body

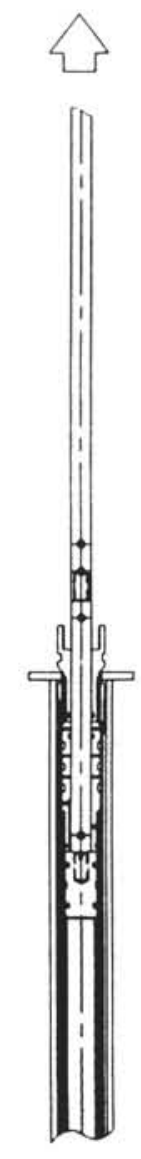

10

Raise upper

latch body with piston rod until fully retracted

Figure 7 (continued). 


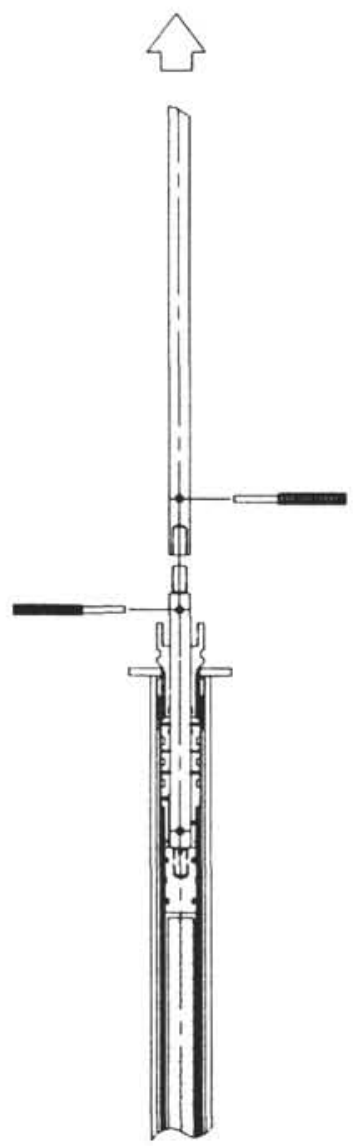

11

Unscrew upper piston rod from lower piston rod with wrenches

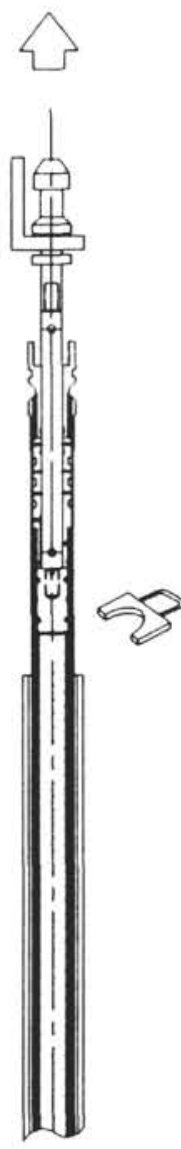

12

Attach lifting angle around pulling neck sub, pull c-plate and raise inner tube and shelby tube out of pipe
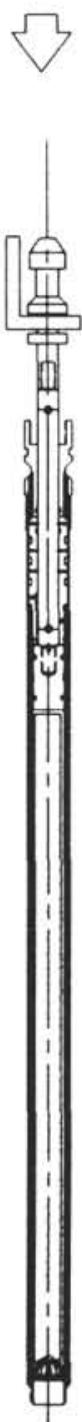

13

Lower inner tube with shelby sampler to rig floor

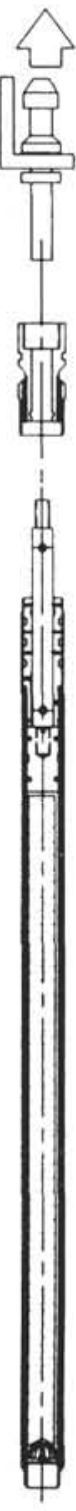

14

Remove lifting sub and lower body assembly from inner tube

Figure 7 (continued).

amounted to approximately $9.5 \mathrm{hr}$ with 6 deployments. The new spindle-bearing housing designed to retain the bearings in case of failure also helped to prevent grease from escaping from the bearings and was thought to be an improvement over the conventional housing. Due to the difficulties associated with the secondary heave compensator in keeping the bit on bottom of the hole, the new float-valve set-up was never tried. We suggest that a softer, more pliable plastic float valve be designed if it is to be run in the coring mode. We thought that the plastic prototype might interfere with the inner barrel, causing it to rotate with the outer barrel. The hardness of the plastic fingers might also restrict logging tools upon retrieval back into the barrel.

Because the formation was extremely hard on Leg 142, the additional sampling tools developed for use with the coring system were never required. The fishing tools developed to assist in the recovery of lost inner or outer barrels were also not required. Several core-lifter cases were damaged during the course of attempting to core before the heave compensator was brought under control. The only other piece of core-barrel hardware damaged was a reamer shell. This occurred on the second bit run where the outer diameter (OD) gage across the first two pads of the reamer was worn back to the 3.75 in. OD $(9.53 \mathrm{~cm})$ of the core barrel. This damage was most likely the result of penetration into the hard formation after the diamond bit was damaged and had lost OD gage.

\section{Diamond Bits}

The first bit selected to be run was a Longyear Series 2 . This bit was manufactured with an extended crown as a means to extend bit life. An estimated $7 \mathrm{~m}$ of fill (approximately $7 \mathrm{~m}$ ) had been swabbed into the bore of the centralization string when a core barrel had been 


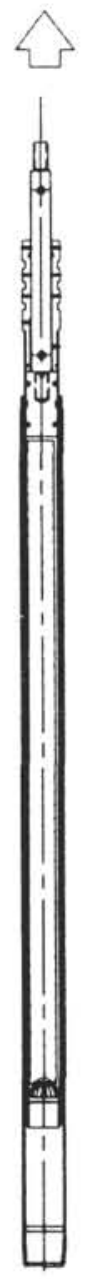

15

Lift out shelby

tube sampler

from inner tube

Figure 7 (continued).
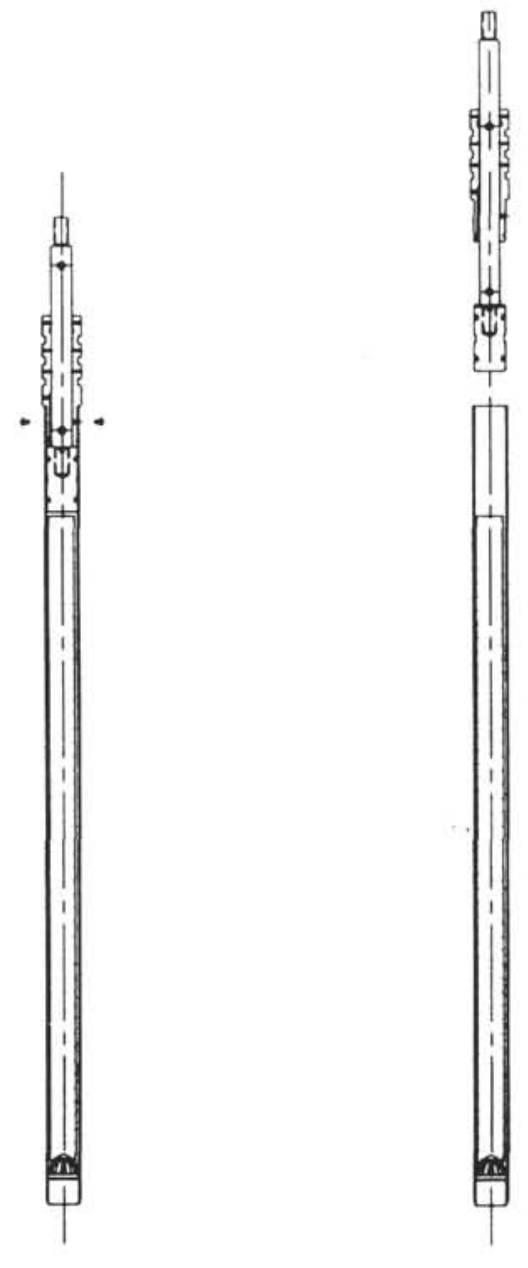

17

Remove lower piston and rod from shelby tube

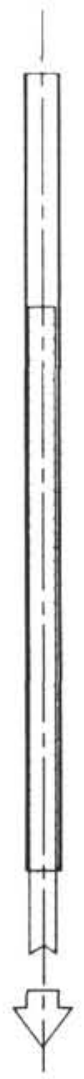

18

Remove catcher and extrude sample from shelby tube with sample extruder retrieved too fast after initial baseline pumping tests were completed. This bit was used in conjunction with a center bit to gently remove the fill prior to coring into the open hole. Rotational speeds of $100 \mathrm{rpm}$ were maintained with light bit weights while removing the fill. Cuttings were allowed to return up the annulus of the mini-riser to the JOIDES Resolution, as other flow paths had plugged off. The secondary heave compensator was not operated during this time, as it was not functional; also, weather conditions favored drilling without it. Just after passing out the end of the primary drill-in bottom-hole assembly (DI-BHA) the center bit was replaced with the core barrel.

The center bit did not reveal any noticeable signs of wear or abrasion. A few of the surface-set stones were missing but in a totally random pattern. The Series 2 bit rotated less than $1 \mathrm{hr}$ before the bit plugged off. Attempts to use the heave compensator were being made during this time. Wide ranges of weight-on-bit fluctuations and bit pounding were experienced in the short interval that it drilled. Once the core barrel was pulled it was obvious that the core bit was broken up and worn away approximately $1 \mathrm{in} .(25.4 \mathrm{~mm})$ from the face of the original crown. The core-lifter case on the end of the inner barrel was missing about $1 / 4$ in. $(6.35 \mathrm{~cm})$ of its length. This damage, coupled with the inner barrel having to be jarred out of the core barrel, was proof enough that the bit was totally missing the crown. Another inner barrel was dropped into the core barrel as a check to see if it would latch in properly. It also had to be jarred out, further verifying that the bit was totally damaged.

The DCS string was pulled so that the bit could be changed, along with any other components that may have suffered damage due to the pounding on the hard formation at the bottom of the hole. Once on deck, the bit looked almost exactly as expected. A couple of additional telltale signs were also visible on the bit, in addition to the missing $1 \mathrm{in} .(25.4 \mathrm{~cm})$ of bit body and matrix. The box connection of the bit was slightly belled, and the remaining face was somewhat ragged around the ID. There were no signs of heat cracks, indicating that the damage was done quickly.

The second bit run was a Hobic Series 1 with an extended crown profile. Upon deploying this bit the hole was deepened to $43.6 \mathrm{ft}$ (13.3 
Table 1. Diamond bits for DCS core barrel, Leg 142.

\begin{tabular}{|c|c|c|c|c|c|c|c|c|}
\hline Item & $\begin{array}{l}\text { Length } \\
\text { (in.) }\end{array}$ & Manufacturer & Matrix type & Grade & $\begin{array}{l}\text { Stones per } \\
\text { carat/ } \\
\text { Set weight }\end{array}$ & Profile & Waterways & $\begin{array}{l}\text { Size } \\
\text { (in.) }\end{array}$ \\
\hline 1 & 6.31 & Longyear & Series 2 & $100 \mathrm{~A}$ & $25 / 35-145$ & Flat & 10 & $1 / 8 \times .438$ \\
\hline 2 & 6.31 & Longyear & Series ID & $100 \mathrm{~A}$ & $25 / 35-191.25$ & Flat & 10 & $1 / 8 \times .438$ \\
\hline 3 & 6.94 & Dimatec & MX6 (med/hard) & $100 \mathrm{~A}$ & $30 / 50-121$ & Flat & 8 & $.31 \times .65$ \\
\hline 4 & 6.94 & Dimatec & MX6 (med/hard) & $100 \mathrm{~A}$ & $30 / 50-121$ & Flat & 8 & $.31 \times .65$ \\
\hline 5 & 6.50 & Hobic & Series 1 & $100 \mathrm{~S}$ & $20 / 25-100$ & Flat & 8 & $.125 \times .46$ \\
\hline 6 & 6.50 & Hobic & Series 2 & $100 \mathrm{~S}$ & $20 / 25-100$ & Flat & 8 & $.125 \times .46$ \\
\hline 7 & 6.31 & Huddy & Silver/blue & N/A & N/A & Flat & 5 & $.197 \times .29$ \\
\hline 8 & 6.31 & Huddy & Yellow & N/A & N/A & Flat & 5 & $.197 \times .29$ \\
\hline 9 & 6.31 & Huddy & Yellow & N/A & N/A & Flat & 5 & $.197 \times .29$ \\
\hline 10 & 6.31 & Huddy & Gold & N/A & N/A & Flat & 5 & $.197 \times .29$ \\
\hline 11 & 6.31 & Huddy & Surface set & $\mathrm{AA}$ & $18-20 / 43$ & $\operatorname{Mod} X$ & N/A & N/A \\
\hline 12 & 6.31 & Huddy & Surface set & AA & $25-40 / 37$ & $\operatorname{Mod} X$ & N/A & N/A \\
\hline 13 & 6.31 & Huddy & Surface set & $\mathrm{AA}$ & $25-40 / 37$ & $\operatorname{Mod} X$ & N/A & N/A \\
\hline 14 & 6.31 & Longyear & Series 2 & $100 \mathrm{~A}$ & $25 / 35-80.75$ & Flat & 10 & $1 / 8 \times 1 / 4$ \\
\hline 15 & 6.31 & Longyear & Series 2 & $100 \mathrm{~A}$ & $25 / 35-80.75$ & Flat & 10 & $1 / 8 \times 1 / 4$ \\
\hline 16 & 6.31 & Longyear & Series 2 & $100 \mathrm{~A}$ & $25 / 35-80.75$ & Flat & 10 & $1 / 8 \times 1 / 4$ \\
\hline 17 & 6.31 & Longyear & Series 6 & $100 \mathrm{~A}$ & $30 / 40-72$ & Flat & 12 & $1 / 8 \times .313$ \\
\hline 18 & 6.31 & Longyear & Series 6 & $100 \mathrm{~A}$ & $30 / 40-72$ & Flat & 12 & $1 / 8 \times .313$ \\
\hline 19 & 6.31 & Longyear & Series 6 & $100 \mathrm{~A}$ & $30 / 40-72$ & Flat & 12 & $1 / 8 \times .313$ \\
\hline 20 & 6.31 & Longyear & Series 6 & $100 \mathrm{~A}$ & $30 / 40-72$ & Flat & 12 & $1 / 8 \times .313$ \\
\hline 21 & 6.31 & Dimatec & M7HP & $100 \mathrm{~A}$ & $30 / 50-79.8$ & V-ring & $10 / 10$ & $3 / 16 \times .44$ \\
\hline 22 & 6.31 & Dimatec & M6HP & $100 \mathrm{~A}$ & $30 / 50-79.8$ & V-ring & $10 / 10$ & $3 / 16 \times .44$ \\
\hline 23 & 6.31 & Hoble & Geoset & Geoset & 130 Geosets & W & N/A & N/A \\
\hline 24 & 6.31 & Huddy & Surface set & AA & $18 / 20-43$ & $\operatorname{Mod} X$ & N/A & N/A \\
\hline 25 & 6.43 & Longyear & Surface set & Premium & $35 / 45-37.25$ & $\mathrm{X}$ & 8 & $3 / 16 \times 3 / 32$ \\
\hline 26 & 6.43 & Longyear & Surface set & Premium & $35 / 45-37.25$ & $\mathrm{x}$ & 8 & $3 / 16 \times 3 / 32$ \\
\hline 27 & 6.43 & Longyear & Surface set & Premium & $15 / 25-38.25$ & $\mathrm{X}$ & 8 & $3 / 16 \times 3 / 32$ \\
\hline 28 & 6.31 & Longyear & Series 6 & $100 \mathrm{~A}$ & $30 / 40-72$ & Flat & 12 & $1 / 8 \times .313$ \\
\hline 29 & 6.31 & Longyear & Series 6 & $100 \mathrm{~A}$ & $30 / 40-72$ & Flat & 12 & $1 / 8 \times .313$ \\
\hline 30 & 6.31 & Longyear & Series 6 & $100 \mathrm{~A}$ & $30 / 40-72$ & Flat & 12 & $1 / 8 \times .313$ \\
\hline
\end{tabular}

Notes: All bits have 3.96-in. outer diameter and 2.20-in. inner diameter. Huddy bits have 5 face discharge ports of $5 \mathrm{~mm}$. N/A =not applicable.

meters below seafloor, or mbsf) and the secondary stage DI-BHA had been set. This allowed a clean and cased hole for the second bit to begin coring in. Compensator problems, coupled with inaccurate load-cell readings, still plagued the amount of weight that the bit was seeing. Some slight advancement was made with the bit before similar signs on the core-lifter case revealed that the bit was again totally destroyed. Total rotational time on the bit was $2 \mathrm{hr}$. Upon tripping the bit to the surface, the total length of the bit had been reduced to $4-3 / 8 \mathrm{in}$. (11.1 cm) from an initial length of $6-1 / 2$ in. $(16.5 \mathrm{~cm})$. The box connection was not belled like the first bit. The remaining bit body showed signs of wear similar to those seen on the first bit; however, the nose section of the core-lifter case was ragged, with large indentations that clearly indicate that the bit was pounded on the bottom of the hole.

The third bit run back in the hole was a Hobic Series 2. Since the two previous bit were hard matrix bits (Series 1), we thought that possibly a slightly softer matrix might provide some additional damping until the problems with the compensator could be sorted out. The core bit was run with a Longyear surface-set center bit as a protective measure against damaging the ID gage of the bit until the compensator was deemed operational. Several changes had been made in the compensator settings, and some hardware problems were corrected with the accumulator before another attempt to drill was initiated. Once the bit was landed approximately 1 to $1.5 \mathrm{~m}$ of fill were noticed in the bottom of the hole. This material was slowly drilled out, but problems with the compensator were still subjecting the core bit/center bit to large swings in bit weight and occasional impacts into the seafloor. Once the fill was drilled, the center bit was recovered before a core-ahead mode was tried. The center bit returned with well over $1-1 / 4$ in. $(3.17 \mathrm{~cm})$ missing from the face. At this point it was obvious that the core bit was also ruined and that any further attempts to core in this hole, even if the compensator problems could be corrected, were futile due to the amount of junk left in the bottom of the hole. Total rotational time on the bit was less than $5 \mathrm{hr}$. The core bit was reduced in length from $6-1 / 2$ in. $(16.5 \mathrm{~cm})$ to $3-5 / 8 \mathrm{in} .(9.2 \mathrm{~cm})$ without any new hole made. The bit body and lower reamer shell were heavily scarred, with deep grooving that indicated either the bit matrix and/or the formation were taking their toll on the equipment as well.

\section{SUGGESTED IMPROVEMENTS}

A number of small refinements can still be made to the system to enhance core recovery with the DCS core barrel. Some of these are listed below, along with some additional hardware for future nested component needs if the DCS tubing itself is to eventually evolve into the third casing string. These suggestions are as follows:

1. Add nickel cadmium plating or similar coating inside the inner barrel.

2. Add extruded aluminum liners.

3. Develop a 3.96-in. (100.6 mm) mill.

4. Investigate designing $\mathrm{N}$-size inner barrel to be used in the existing H-size outer core barrel in order to reduce swabbing effects while retrieving the barrel.

5. Investigate $\mathrm{N}$-size coring system crossing over to the DCS tubing above seafloor.

6. Strengthen full-round wrenches.

7. Modify reamer shell and adapter coupling design to allow more area for gripping with make-up and break-out wrenches.

8. Investigate whether tapered inner barrels can be used with the existing hardware.

9. Develop a retractable wireline core-bit system.

\section{REFERENCE}

Storms, M.A., Natland, J.H., et al., 1991. Proc. ODP, Init. Repts., 132: College Station, TX (Ocean Drilling Program).

\section{Ms 142IR-110}




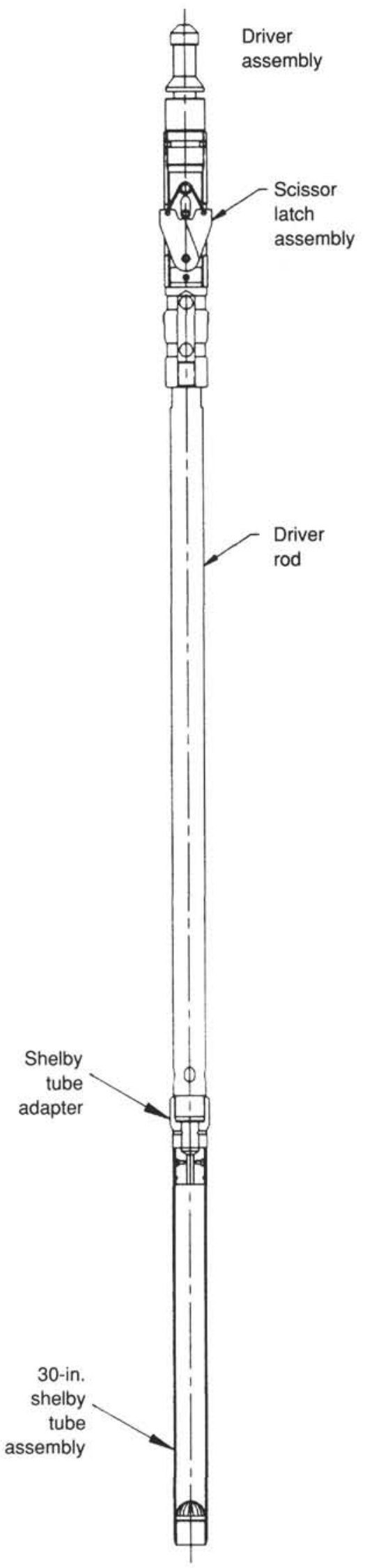

Figure 8. DCS push sampler. 


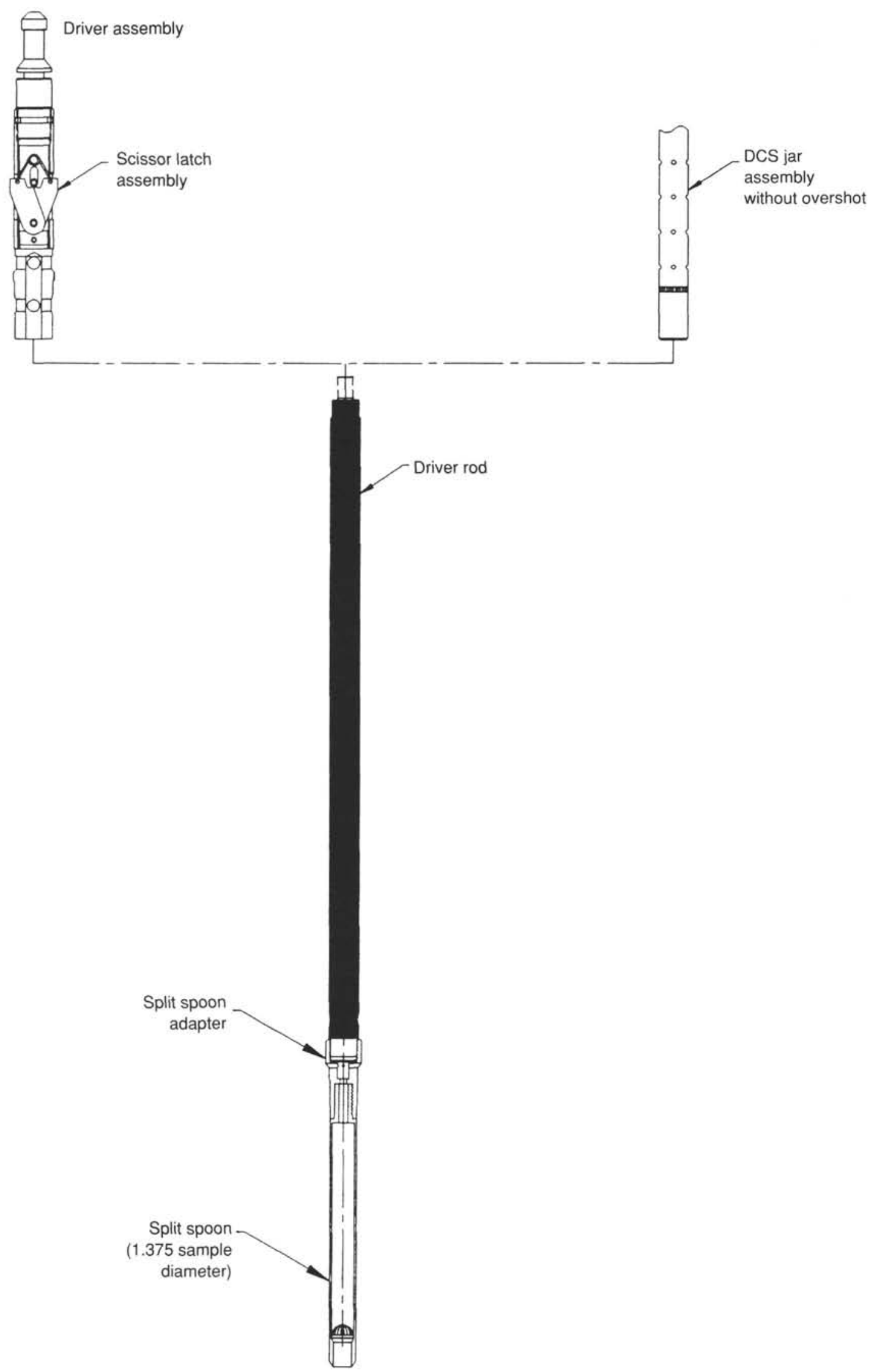

Figure 9. DCS percussion sampler. 


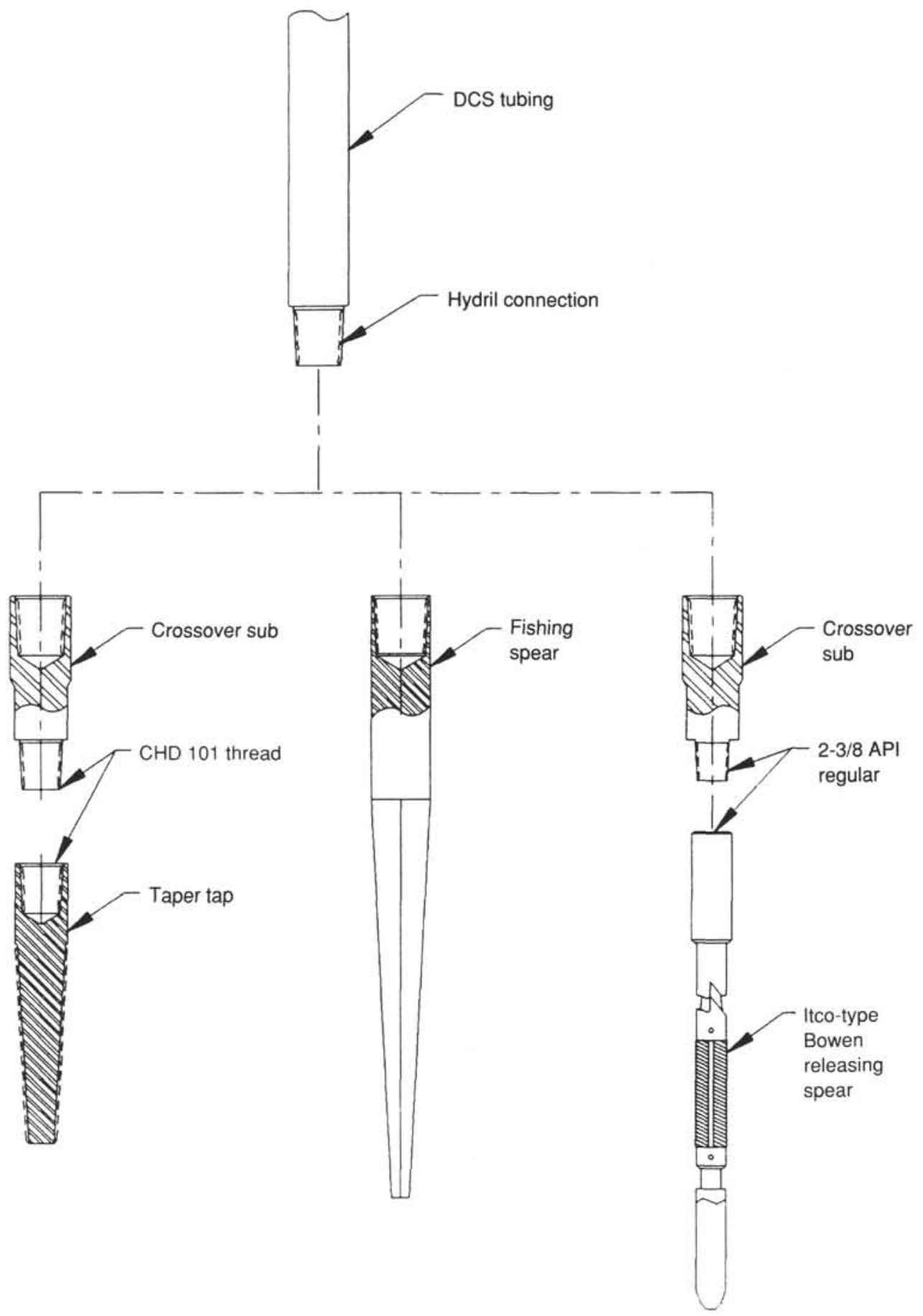

Figure 10. Fishing tool options for DCS tubing. 


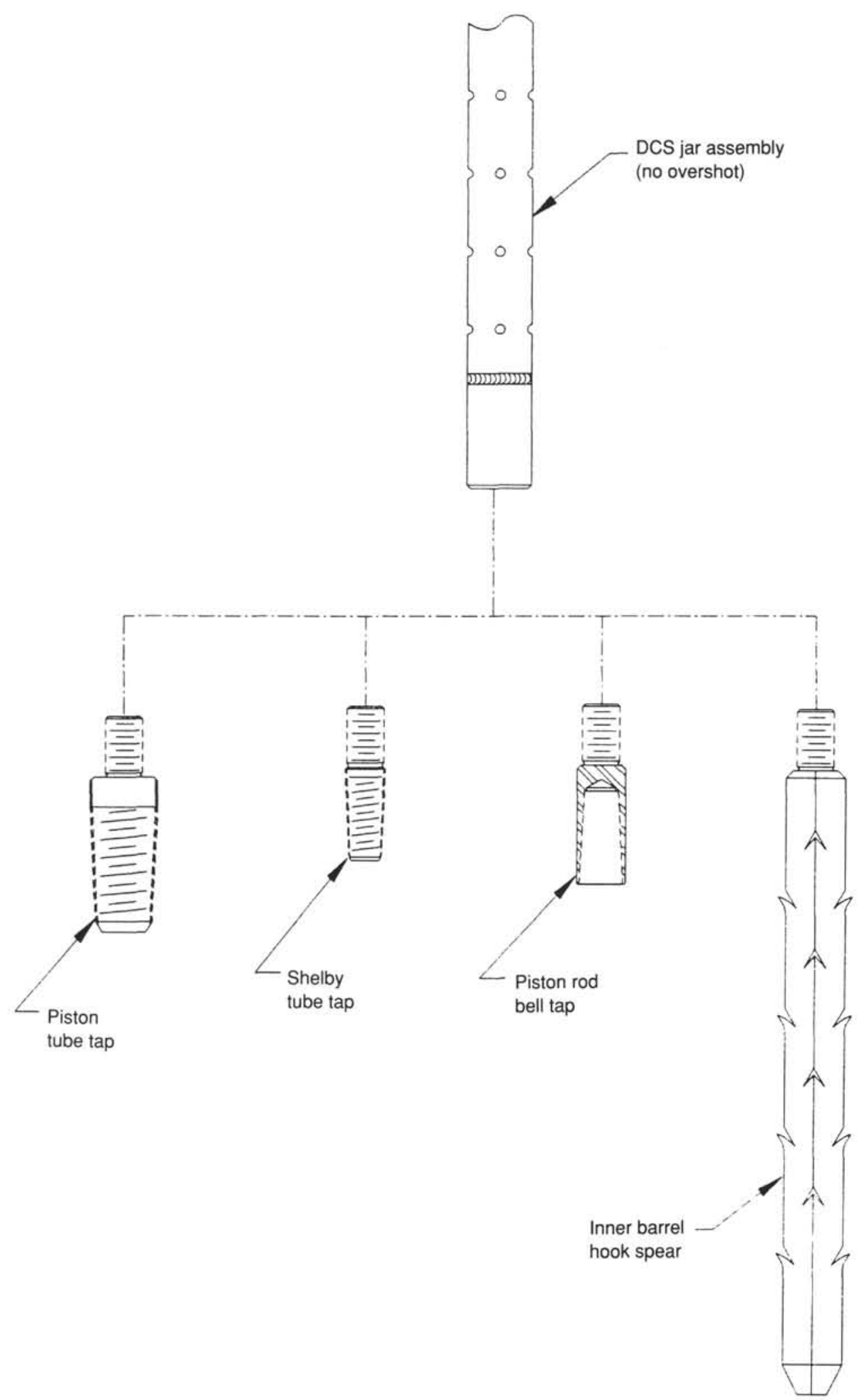

Figure 11. Inner barrel/piston-sampler fishing options. 